\title{
КЛИНИЧЕСКИЙ СЛУЧАЙ МОНОГЕННОЙ ФОРМЫ САХАРНОГО ДИАБЕТА ТИПА С ГЕТЕРОЗИГОТНОЙ МУТАЦИЕЙ В ГЕНЕ $C E L$
}

\author{
Копытина Д.А., Сечко Е.А., Романенкова Е.М., Лаптев Д.Н.
}

ФГБУ «НМИЦ Эндокринологии» Минздрава России, Москва, Россия

Ключевые слова: MODY, Maturity-Onset Diabetes of the Young, ген CEL

Гетерозиготные мутации в гене $C E L$ - редкая причина моногенного сахарного диабета (CД) (MODYCEL или MODY8). В настоящее время описано 8 семей с MODY-CEL. Возраст диагностики CД, как правило, инсулинзависимого, после 25 лет. Для данного заболевания характерно сочетание экзокринной и эндокринной дисфункции поджелудочной железы, однако описаны случаи изолированной эндокринной недостаточности.

Цель: Описание клинического случая пациента с моногенным СД, обусловленным гетерозиготной мутацией в гене $C E L$

Клинический случай: Пациентка Р, 12 лет, поступила в детское отделение сахарного диабета ФГБУ "НМИЦ эндокринологии" Минздрава России с жалобами на повышение гликемии натощак.

Из анамнеза известно, что в возрасте 11 лет при диспансерном осмотре выявлена гипергликемия натощак до 5,8 ммоль/л. При дальнейшем обследовании HbA1c 6,8\%, гликемия натощак - 6,62 ммоль/л. Аглюкозурия. Специфические панкреатические аутоантитела (GAD, IAA, ICA) (AT) отрицательные. Установлен диагноз: Нарушение толерантности к глюкозе, назначен метформин 250 мг/сутки без положительного эффекта, через 4 месяца терапия отменена. В домашних условиях гликемия натощак 6,5-7,0 ммоль/л.

Наследственный анамнез: отец, бабушка по отцовской линии - СД без избыточной массы тела, сахароснижающую терапию не получают. У отца HbA1c - 6,5\%.

При обследовании в ФГБУ «НМИЦ Эндокринологии» в возрасте 12 лет (длительность заболевания 1 год): рост 152,6 см; масса тела 48,4 кг, ИМТ 20,8 кг/м2, SDS ИМТ 0,786. При поступлении терапию сахароснижающими препаратами не получала. HbA1c - 6,2\%. По данным ОГТТ уровень глюкозы на 0 мин - 6,08 ммоль/л, на 60 мин - 10,07 ммоль/л, на 120 мин - 9,04 ммоль/л; уровень ИРИ на 0 мин 9,42 мкЕд/мл, на 60 мин - 156,5 мкЕд/мл, на 120 мин - ИРИ 143,9 мкЕд/мл. Индекс НОМА 2,55 (<3,2). Таким образом, выявлены нарушение гликемии натощак и нарушение толерантности к глюкозе, гиперинсулинемия без инсулинорезистентности. AT (GAD, IA2) - отрицательные. Рекомендована диетотерапия.

Учитывая непрогрессирующий характер нарушений углеводного обмена, высокую, сохранную секрецию инсулина, отсутствие потребности в сахароснижающей терапии при длительности заболевания 1 год, отягощенный наследственный анамнез по СД в трех поколениях, отрицательный титр АТ, заподозрена моногенная форма сахарного диабета. По данным молекулярно-генетического исследования выявлен гетерозиготный, ранее неописанный, патогенный вариант p.A131PfsX67 в гене CEL.

Повторно девочка обследована в ФГБУ "НМИЦ эндокринологии" Минздрава России в 12,5 лет (длительность заболевания - 1,5 года). На фоне диеты гликемия 6,8-9,3 ммоль/л, НbА1c - 6,1\%. Панкреатическая эластаза кала более 500 мкг/г, что позволило исключить экзокринную недостаточность поджелудочной железы.

Заключение: Сахарный диабет MODY-CEL - это редкая форма моногенного СД, характеризующаяся мутацией в гене $C E L$ (липолитический фермент эфира карбоновой кислоты), приводящий к медленно прогрессирующей экзокринной дисфункции поджелудочной железы с липоматозом, образованием кист поджелудочной железы с последующим присоединением недостаточности $\beta$-клеток. В описанных ранее случаях MODY-CEL диагностирован в возрасте $>25$ лет. Данный клинический 
случай демонстрирует диагностику заболевания в детском возрасте с асимптоматической гипергликемии, не требующей назначения сахароснижающей терапии. По мере прогрессирования заболевания можно ожидать присоединение экзокринной дисфункции поджелудочной железы с последующим истощением инсулярного аппарата $\beta$-клеток, которое потребует назначение инсулинотерапии. 